\title{
Leukocyte coping capacity as a complementary stress metric in migrating birds
}

\author{
Nikolaus Huber ${ }^{1,3}$ (1) Virginie Canoine ${ }^{2} \cdot$ Jessica S. Cornils ${ }^{3} \cdot$ Ivan Maggini $^{1} \cdot$ Massimiliano Cardinale $^{4} \cdot$ Thomas Ruf $^{3}$. \\ Leonida Fusani ${ }^{1,2}$
}

Received: 20 December 2019 / Accepted: 23 March 2020 / Published online: 1 April 2020

(c) The Author(s) 2020

\begin{abstract}
Corticosterone (Cort) is involved in multiple physiological processes during bird migration, complicating its interpretation in a stress context. We investigated whether the leukocyte coping capacity (LCC) provides useful complementary information on the stress response in migratory Garden Warblers (Sylvia borin) and how it relates to Cort and energetic condition. Contrary to Cort levels, LCC significantly decreased, implying high-stress levels and a diminished capacity to recover after a stressful event. The absence of significant effects of body conditions on the stress parameters shows no simple relationship between these traits and highlights the need for additional stress metrics to measure stress in life-history contexts.
\end{abstract}

Keywords Migration $\cdot$ Stress $\cdot$ Coping $\cdot$ Leukocyte coping capacity $\cdot$ Endocrine-immune system

\section{Zusammenfassung}

\section{„Leukocyte coping capacity“ als ergänzende Messung von Stress bei sich im Zug befindenden Vögeln}

Die gleichzeitige Beteiligung von Kortikosteron (Cort) an mehreren verschiedenen physiologischen Prozessen während der Wanderung von Zugvögeln erschwert dessen Interpretation im Zusammenhang mit Stress. Wir untersuchten bei sich im Zug befindlichen Gartengrasmücken (Sylvia borin), ob die Methode „Leukocyte coping capacity “ (LCC) nützliche und ergänzende Informationen bezüglich der Stressantwort liefert und wie diese mit Cort und dem energetischen Zustand der Vögel zusammenhängen könnte. Im Gegensatz zu Cort nahm die LCC signifikant ab. Dies deutet auf erhöhten Stress und eine verminderte Erholungskapazität nach einem Stressereignis hin. Das Ausbleiben signifikanter Effekte zwischen

Communicated by N. Chernetsov.

Electronic supplementary material The online version of this article (https://doi.org/10.1007/s10336-020-01774-9) contains supplementary material, which is available to authorized users.

Nikolaus Huber

nikolaus.huber@vetmeduni.ac.at

Virginie Canoine

virginie.canoine@univie.ac.at

Jessica S. Cornils

jessica.cornils@vetmeduni.ac.at

Ivan Maggini

ivan.maggini@vetmeduni.ac.at

Massimiliano Cardinale

massimiliano.cardinale@slu.se

Thomas Ruf

thomas.ruf@vetmeduni.ac.at

Leonida Fusani

leonida.fusani@vetmeduni.ac.at; leonida.fusani@univie.ac.at
1 Department of Interdisciplinary Life Sciences, Konrad Lorenz Institute of Ethology, University of Veterinary Medicine Vienna, Savoyenstraße 1, 1160 Vienna, Austria

2 Department of Behavioural and Cognitive Biology, University of Vienna, Althanstraße 14, 1090 Vienna, Austria

3 Department of Interdisciplinary Life Sciences, Research Institute of Wildlife Ecology, University of Veterinary Medicine, Savoyenstraße 1, 1160 Vienna, Austria

4 Department of Aquatic Resources, Institute of Coastal Research, Swedish University of Agricultural Sciences, Uppsala, Sweden 
Körperkondition und den erhobenen Stressparametern zeigt, dass kein einfacher Zusammenhang zwischen Stressparametern und Körperkondition besteht und unterstreicht die Notwendigkeit zusätzlicher Methoden zur besseren Messung von Stress in verschiedenen Life-history Abschnitten.

\section{Introduction}

Measuring corticosterone concentrations (Cort) has been adopted as the standard method to assess stress levels in birds. Cort, however, is one of many components of the stress response and has the primary function of mobilising energy, with other pleiotropic effects (MacDougall-Shackleton et al. 2019). This fact becomes particularly evident in the context of bird migration (Eikenaar et al. 2018). Baseline and stress-induced Cort levels differ between spring and fall migration, are likely to be species-specific and show sizeable individual variation (Tsvey et al. 2019). Measuring Cort doubtlessly gives valuable information regarding the activation of the hypothalamic-pituitary-adrenal (HPA) axis in response to internal/organismal and external/environmental stressors (Romero \& Wingfield 2015). However, considering the involvement of Cort in multiple physiological processes during migration, the question arises whether its use as a stand-alone measure is comprehensive enough to reflect an individual's stress condition in this specific life-history state. Other physiological pathways, such as the endocrineimmune interface may provide additional insights into stress associated trade-offs and biological costs but are rarely studied. Based on the observation that leukocytes of stressed individuals have a reduced capacity to produce reactive oxygen species (ROS) in response to a secondary (chemical) external stimulus, several studies on mammals have used a method called leukocyte coping capacity (LCC; leukocyte ROS production; McLaren et al. 2003) as a proxy for stress (reviewed by Huber et al. 2019). Recently, we showed in captive House Sparrows (Passer domesticus) that the immunological tool LCC may provide a more integrative perspective on the effects of stress rather than being just one of its constituent mediators (Huber et al. 2017).

Here we provide a first study of LCC during migration in wild Garden Warblers (Sylvia borin), a long-distance passerine migrant. To explore whether the LCC method may provide useful complementary information on the stress response of birds during migration, we combined the classical capture-handling stress protocol (Wingfield and Ramenofsky 1999) with the LCC approach. As several studies report a connection between energy stores and Cort responses in migrating birds (Eikenaar et al. 2018), we recorded body condition to investigate the relationships between Cort response, LCC and energetic condition.

\section{Methods}

The study was conducted on Ponza $\left(40^{\circ} 50^{\prime} \mathrm{N}, 12^{\circ} 58^{\prime} \mathrm{E}\right)$, a small island located along one of the central Mediterranean migratory corridors, which is used as a stopover site for several migratory species. We captured 17 Garden Warblers of unknown sex and age with mist nets during spring migration (8th-19th of May 2016). Blood samples were taken between 06:30 and 18:00 from the brachial vein within $<3 \mathrm{~min}$ (mean $\pm \mathrm{SD}=1.96 \pm 0.47 \mathrm{~min} ; \mathrm{T} 0)$ and after 15 and $30 \mathrm{~min}$ when a bird flew into the net (T15 and T30). Between samplings, birds were kept inside a cloth bag. Subsequently, we scored subcutaneous fat, pectoral muscle size, length of the 3rd primary cover (P3) and body mass. Using body mass and P3, we calculated a scaled Body Mass Index (BMI; for details see Peig and Green 2009 and the online supplementary material). To quantify total plasma Corticosterone, we used the Cort $^{125}$ I radioimmunoassay kit (Catalogue No. 07-120102; MP Biomedicals, Solon, OH, USA). For one individual, T15 Cort was not analysed due to an insufficient amount of plasma. For LCC analysis, we followed the protocol previously published in Huber et al. (2017). Briefly, $20 \mu \mathrm{l}$ of heparinised whole blood was used to quantify leukocyte ROS production via chemiluminescence measured for $30 \mathrm{~s}$ every $10 \mathrm{~min}$ over $80 \mathrm{~min}$ by a portable chemiluminometer (Junior LB 9509, EG and G Berthold, Germany). The detailed assay protocols are provided in the online supplementary material.

\section{Statistical analysis}

Based on Cort levels at the three sampling time points, we calculated the area under the curve (AUC; also termed integrated Cort; Lattin and Kelly 2020) to ground $\left(\mathrm{AUC}_{\mathrm{g}}\right.$; i.e., total Cort) and the AUC to increase $\left(\mathrm{AUC}_{\mathrm{i}}\right.$; i.e., corrected for Cort at T0) for each individual (for details see Pruessner et al. 2003). To account for possible non-linear time courses of Cort and LCC measurements, we used sampling time (calculated as hours after sunset) and sampling date as factorial variables and assessed their overall effect with an ANOVA. Post-hoc comparisons between sampling times were carried out with Tukey-type tests. We used Pearson correlation coefficients to test the relationship of Cort at T0, $\mathrm{AUC}_{\mathrm{g}}$ and $\mathrm{AUC}_{\mathrm{i}}$ to time of the day. As there was no significant effect, sampling date or time were not included in subsequent analysis to increase parsimony of the models. We analysed the effects of body mass, fat, muscle score and BMI on Cort and LCC levels at T0, T15 and T30 using linear 
mixed-effects models with individual intercepts as a random factor to account for repeated measures. Effects of the same variables on Cort-AUC $\mathrm{g}_{\mathrm{g}}$ and $-\mathrm{AUC}_{\mathrm{i}}$, respectively were analysed using log-linear models (note: no repeated measurement data in these models). Based on Akaike's Information Criterion corrected for small sample sizes, we selected the best model by computing all possible additive models. We limited the model selection to models without interactions to avoid overfitting. Two more linear mixed-effects models were run to analyse interrelation between (i) single Cort and LCC levels and (ii) LCC peak levels and LCC curve, again including individual ID as a random effect. We inspected residuals from all models for approximate normal distribution using quantile-quantile plots and found no severe deviation from normality after logarithmic transformation of Cort and LCC data. All statistical analyses were carried out in R 3.5.2 (R Core Team 2017). R functions and respective packages are provided in the online supplementary material.

\section{Results}

We found a significant effect of sampling time point on Cort levels $\left(F=21.97, p<0.001, n_{\text {observations }}=50, n_{\text {individuals }}=17\right.$; Fig. 1, Table 1). There was no effect of body mass, fat,

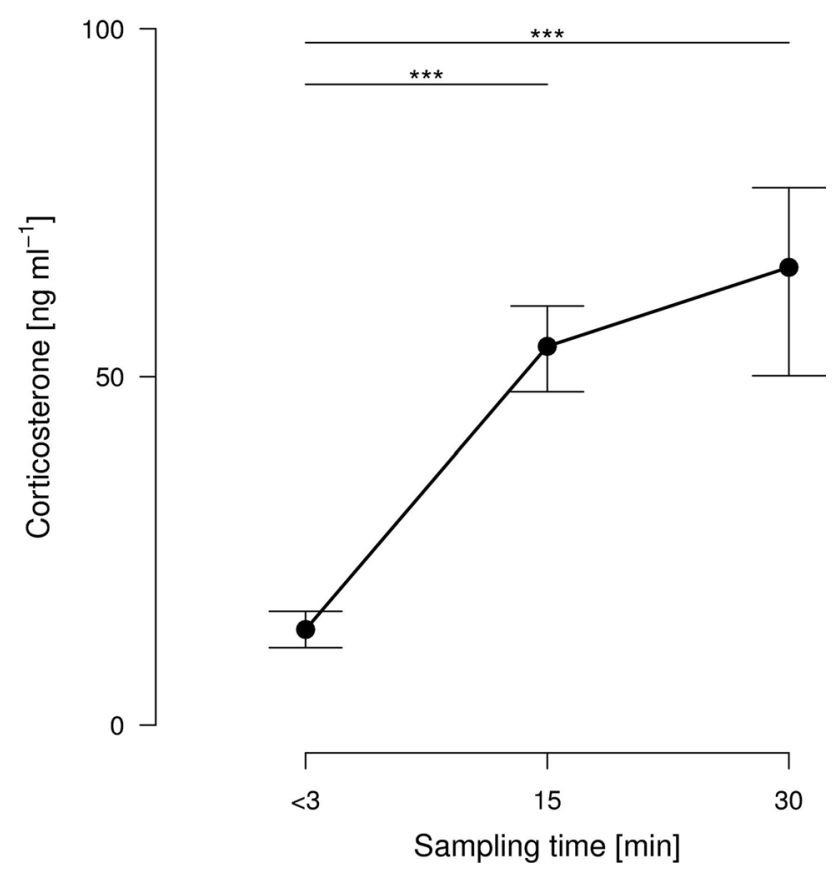

Fig. 1 Adrenocortical response to capture and handling of migrating Garden Warblers caught at a stopover site during spring migration $(n=17)$. Dots represent corticosterone (Cort; mean \pm standard error of the mean) levels at $<3$ min (T0), 15 min (T15) and 30 min (T30) after capture. There was a significant increase in CORT at T15 and $\mathrm{T} 30$ but no significant difference between T15 and T30. $* * * p<0.001$
Table 1 Summary table of the linear model describing the effects of sampling time [immediately after (Intercept), $15 \mathrm{~min}$ (T15), and 30 min (T30) after capture] on CORT levels of 17 Garden Warblers of unknown sex and age $n=17,50$ observations, captured at a stopover site on Ponza island during spring migration

\begin{tabular}{lclll}
\hline & Estimate & $\pm \mathrm{SE}$ & $t$ & $p$ \\
\hline Intercept & 19.37 & 4.6 & 4.14 & $<0.001$ \\
T15 & 1.54 & 0.25 & 6.18 & $<0.001$ \\
T30 & 1.57 & 0.25 & 6.41 & $<0.001$ \\
\hline
\end{tabular}

muscle score, or the calculated BMI on Cort levels at T0, $\mathrm{T} 15$, and $\mathrm{T} 30$, the $\mathrm{AUC}_{\mathrm{g}}$ or the $\mathrm{AUC}_{\mathrm{i}}$ of birds. We report descriptives of these variables in Table 2 . The best models for single Cort levels, $\mathrm{AUC}_{\mathrm{g}}$ and $\mathrm{AUC}_{\mathrm{i}}$, included only bleeding time point as a significant effect. There was no relationship between capture date or time of day and individual Cort levels at $\mathrm{T} 0(r=0.167, p=0.52)$, the $\mathrm{AUC}_{\mathrm{g}}(r=-0.02$, $p=0.93)$ or the $\operatorname{AUC}_{\mathrm{i}}(r=-0.168, p=0.53)$. Further, there was no significant correlation between single Cort and LCC peak levels (slope $\pm \mathrm{se}=-0.01 \pm 0.01, t=-1.54, p=0.134$, marginal $R^{2}=0.05 ; n_{\text {obs }}=50, n_{\text {ind }}=17$ ).

LCC peak levels decreased linearly with sampling time (slope \pm se $=-0.34 \pm 0.087, p<0.001 ; n_{\text {obs }}=51$, $n_{\text {ind }}=17$ ) (Fig. 2). We did not find a significant effect of body mass, fat score, muscle score, or BMI on LCC peak levels in our individuals (all $p$ values $>0.15$ ). LCC peak levels and LCC AUC were highly significantly correlated ( slope $\pm \mathrm{se}=0.02 \pm 0.0004, t=60.65, p=<0.0001$, marginal $R^{2}=0.98 ; n_{\text {obs }}=51, n_{\text {ind }}=17$; suppl Fig. 1 ), revealing that LCC peak levels are a good proxy for the entire LCC response over $80 \mathrm{~min}$.

\section{Discussion}

The relatively low T0 Cort and its significant increase thereafter (Fig. 1) are in line with other studies in Garden Warblers during migration and stopover (Schwabl et al. 1991; Tsvey et al. 2019). The observed pattern corroborates findings suggesting that endurance flight and fasting

Table 2 Minimum (Min), maximum (Max), means and standard deviations $( \pm \mathrm{SD})$ of morphological- and body condition measurements from 17 Garden Warblers of unknown sex and age, captured at a stopover site on Ponza island during spring migration

\begin{tabular}{lllcl}
\hline & Min & Max & Mean & $\pm \mathrm{SD}$ \\
\hline Body mass (g) & 12.5 & 18.3 & 15.88 & 1.63 \\
Wing length (P3; mm) & 58 & 63.5 & 61.26 & 1.58 \\
body fat score (0-8) & 0 & 5 & 1.8 & 1.2 \\
muscle score (0-3) & 1 & 3 & 1.9 & 0.5 \\
BMI & 13.36 & 19.64 & 16.43 & 2.11 \\
\hline
\end{tabular}



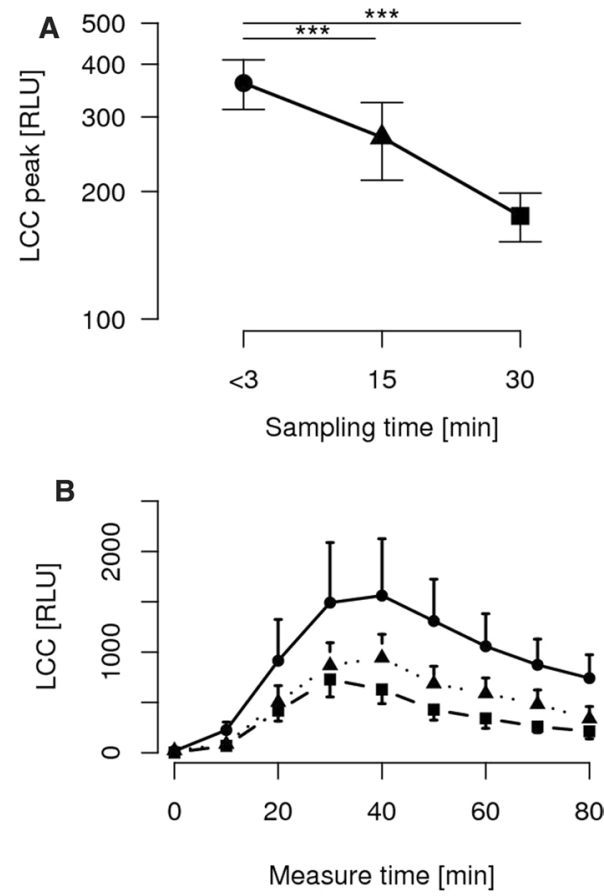

Fig. 2 a Partial regression plot of Leucocyte coping capacity (LCC) peaks in migrating Garden Warblers captured at a stopover site during their spring migration (mean \pm standard error of the mean (SEM); $n=17$ ). LCC was measured in blood samples taken at $<3$ min (T0), $15 \mathrm{~min}$ (T15) and $30 \mathrm{~min}$ after capture (T30) and is expressed in relative light units (RLU). b Complete LCC curve patterns for the respective sampling time points (mean \pm SEM). The shape of the curve represents the real-time increase and decrease of reactive oxygen species in the frame of the leukocyte oxidative burst response. The maximum capacity is reached at about $40 \mathrm{~min}$ with a subsequent decrease indicating a depletion of the cells. ${ }^{* * *} p<0.001$ and ${ }^{*} p<0.05$

during migration are not stressors per se as long as energy stores are sufficient (Jenni-Eiermann et al. 2009; Schwabl et al. 1991). For the first time, we report a physiological response to restraint stress during the migratory period using LCC, where LCC levels significantly decreased with sampling time. In general and independently of life-history stages, low LCC levels and no recovery or a decrease in LCC within 30 min after a short-term stress event suggest high-stress levels and diminished capacity of the organism to effectively cope with and recover from stress (Huber et al. 2019; McLaren et al. 2003). The decline in LCC of the current study in all individuals is remarkable since captive house sparrows showed an increase in LCC, interpreted as a partial restoration of the capacity to cope with repeated or novel stress (Huber et al. 2017). As the LCC method is rather novel and data from other bird species are scarce, the observed LCC patterns may also be species-specific, differ between life-history stages (migrating vs non-migrating) as well as different contexts (captive vs free-living).

Despite the significant increase in Cort supporting allostasis, LCC levels of migrating Garden Warblers dropped throughout the 30-min measure period (Fig. 2). One possible explanation may be that high physiological costs during migration diminish the capacity of the animal to recover this crucial innate function immediately after a stressful event. The absence of a significant relationship between body conditions and Cort levels or the LCC response, however, shows that there is no simple relationship between these traits (Schultner et al. 2013). Further studies are necessary to explore LCC dynamics and their usefulness as proxies for stress and to understand how they relate to the broader concept of stress and coping with unpredictable events within different life-history stages.

Acknowledgements Open access funding was provided by University of Veterinary Medicine Vienna. We thank the entire crew of the research centre on bird migration on Ponza Island. Special thanks to Andrea Ferretti for supporting the fieldwork. This is paper no. 67 from the Piccole Isole Project of the Italian National Institute for Environmental Protection and Research (ISPRA; Istituto Superiore per la Protezione e la Ricerca Ambientale).

Author contributions $\mathrm{NH}$ and LF initiated the study. VC, JSC and IM conducted the fieldwork on Ponza Island. MC is the director of the Bird Migration Research Center on Ponza Island and conducted the data acquisition for bird morphology and body conditions as well as provided logistical support. VC performed all hormone assays for corticosterone. TR conducted the data analysis with contributions of NH and JSC. NH wrote the manuscript. LF critically revised the manuscript. All authors provided comments and approved the final version of the manuscript.

Funding The project was supported by funds of the University of Vienna and the University of Veterinary Medicine, Vienna, to LF. The funding source was not involved in the study design, the collection, analysis and interpretation of data, in the writing of the report or the decision to submit the article.

Data availability All data generated or analysed during this study are included in this published article [and its supplementary information files].

\section{Compliance with ethical standards}

Conflict of interests The authors declare that they have no conflict of interest.

Ethical approval All applicable international, national, and institutional guidelines for the care and use of animals (i.e. capture, handling, restrainment and blood sampling) were followed and were authorized by the Regione Lazio in accordance with Italian law.

Open Access This article is licensed under a Creative Commons Attribution 4.0 International License, which permits use, sharing, adaptation, distribution and reproduction in any medium or format, as long as you give appropriate credit to the original author(s) and the source, provide a link to the Creative Commons licence, and indicate if changes were made. The images or other third party material in this article are included in the article's Creative Commons licence, unless indicated otherwise in a credit line to the material. If material is not included in the article's Creative Commons licence and your intended use is not permitted by statutory regulation or exceeds the permitted use, you will 
need to obtain permission directly from the copyright holder. To view a copy of this licence, visit http://creativecommons.org/licenses/by/4.0/.

\section{References}

Eikenaar C, Müller F, Rüppel G, Stöwe M (2018) Endocrine regulation of migratory departure from stopover: evidence from a longitudinal migratory restlessness study on northern wheatears. Horm Behav 99:9-13. https://doi.org/10.1016/j.yhbeh.2018.01.008

Huber N, Fusani L, Ferretti A, Mahr K, Canoine V (2017) Measuring short-term stress in birds: comparing different endpoints of the endocrine-immune interface. Physiol Behav 182:46-53. https:// doi.org/10.1016/j.physbeh.2017.09.017

Huber N, Marasco V, Painer J, Vetter SG, Göritz F, Kaczensky P, Walzer C (2019) Leukocyte coping capacity: an integrative parameter for wildlife welfare within conservation interventions. Front Vet Sci. https://doi.org/10.3389/fvets.2019.00105

Jenni-Eiermann S, Hasselquist D, Lindstrom A, Koolhaas A, Piersma T (2009) Are birds stressed during long-term flights? A windtunnel study on circulating corticosterone in the red knot. Gen Comp Endocrinol 164:101-106. https://doi.org/10.1016/j.ygcen .2009 .05 .014

Lattin CR, Kelly TR (2020) Glucocorticoid negative feedback as a potential mediator of trade-offs between reproduction and survival. Gen Comp Endocrinol 286:113301. https://doi. org/10.1016/j.ygcen.2019.113301

MacDougall-Shackleton SA, Bonier F, Romero LM, Moore IT (2019) Glucocorticoids and "stress" are not synonymous. Integr Organ Biol. https://doi.org/10.1093/iob/obz017

McLaren GW, Macdonald DW, Georgiou C, Mathews F, Newman C, Mian R (2003) Leukocyte coping capacity: a novel technique for measuring the stress response in vertebrates. Exp Physiol 88:541546. https://doi.org/10.1113/Eph8802571

Peig J, Green AJ (2009) New perspectives for estimating body condition from mass/length data: the scaled mass index as an alternative method. Oikos 118:1883-1891. https://doi.org/10.111 1/j.1600-0706.2009.17643.x

Pruessner JC, Kirschbaum C, Meinlschmid G, Hellhammer DH (2003) Two formulas for computation of the area under the curve represent measures of total hormone concentration versus time-dependent change. Psychoneuroendocrinology 28:916-931. https://doi. org/10.1016/S0306-4530(02)00108-7

R Core Team (2017) R: a language and environment for statistical computing. R Foundation for Statistical Computing, Vienna, Austria. R Foundation for Statistical Computing, Vienna, Austria. https:// www.R-project.org/

Schwabl H, Bairlein F, Gwinner E (1991) Basal and stress-induced corticosterone levels of garden warblers, Sylvia borin, during migration. J Comp Physiol B 161:576-580. https://doi.org/10.1007/ BF00260747

Tsvey A, Loshchagina J, Naidenko S (2019) Migratory species show distinct patterns in corticosterone levels during spring and autumn migrations. Anim Migr 6:4-18. https://doi.org/10.1515/ ami-2019-0003

Wingfield JC, Ramenofsky M (1999) Hormones and the behavioral ecology of stress. In: Balm PHM (ed) Stress physiology in animals. Sheffield Biological Sciences. Sheffield Academic Press, Sheffield, pp 1-51

Publisher's Note Springer Nature remains neutral with regard to jurisdictional claims in published maps and institutional affiliations. 